\title{
PRIORITIZATION OF SERVICE QUALITY CRITERIA FOR HOTEL MANAGEMENT SYSTEMS USING ANALYTICAL HIERARCHY PROCESS
}

\section{OTEL YÖNETIM SISTEMLERİ HIZMET KALITTESİ KRITTERLERINIIN ANALİTIK HIYYERARŞI SÜRECI İLE ÖNCELİKLENDİRÍLMESİ}

\author{
Mehmet Emre GÜLER1,* | Aşkın ÖZDAĞOĞLU2 | Can Serkan TUNCAY 3 \\ ${ }^{1}$ Prof. Dr., Turizm İşletmeciliği Bölümü, Turizm Fakültesi, İzmir Katip Çelebi Üniversitesi, İzmir, Türkiye, memre.guler@ikcu.edu.tr, \\ ORCID: 0000-0002-8689-9859 \\ 2 Doç. Dr., İşletme Bölümü, İșletme Fakültesi, Dokuz Eylül Üniversitesi, İzmir, Türkiye, askin.ozdagoglu@deu.edu.tr, \\ ORCID: 0000-0001-5299-0622 \\ 3 Öğr. Gör., İzmir Katip Çelebi Üniversitesi, İzmir, Türkiye, canserkan.tuncay@ikcu.edu.tr, ORCID: 0000-0002-5543-5904
}

\section{Article Info:}

Received : May 7, 2020

Revised : May 25, 2020

Accepted : June 11, 2020

\section{Keywords:}

Hospitality Management

Property Management Systems (PMS)

Analytic Hierarchy Process

(AHP)

Software Service Quality

Anahtar Kelimeler:

Konaklama İsletmeciliği

Otel Yönetim Sistemleri (OYS)

Analitik Hiyerarşi Süreci (AHP)

Yazılım Hizmet Kalitesi

DOI:10.46238/jobda.733618

\begin{abstract}
With the software developed in line with society's needs, the importance of technology is gradually increasing. With this developed software, people and institutions can achieve the most economical results by using less time and labor. In light of these developments, the importance of quality software is also increasing. This study aims to prioritize the service quality of the software used in the accommodation establishments with the Analytical Hierarchy Process (AHP) method of the most commonly used ISO / IEC TS 25011: 2017 software quality model criteria and to determine the best software criteria for users.In the research, after the evaluations regarding software service quality within the framework of ISO / IEC TS 25011: 2017 software quality model, using the AHP, the findings obtained prioritize the criteria regarding Property Management Systems (PMS) software service quality according to tourism and accommodation enterprises. According to the main criteria, the findings were found as "Information Technology Service Adaptability," "Tangibility," "Information Technology Service Maintability," "Information Technology Service Reliability," "Usability," "Enthusiasm," "Security" and "Suitability." These findings will guide the companies that provide software services to tourism and accommodation enterprises to improve the quality of the services.

\section{ÖZET}

Toplumun ihtiyaçları doğrultusunda geliștirilen yazılımlarla birlikte teknolojinin önemi giderek artmaktadır. Geliștirilen yazılımlar sayesinde kişi ve kurumlar, daha az zaman ve iş gücü kullanarak en ekonomik şekilde sonuca ulaşabilmektedirler. Bu gelişmeler ışığında kaliteli yazılımların önemi giderek artmaktadır. Bu çalışmada konaklama işletmelerinde kullanılan yazılımların hizmet kalitesinin, en yaygın olarak kullanılan ISO/IEC TS 25011:2017 yazılım kalite modeli kriterlerinin Analitik Hiyerarşi Süreci (AHP) yöntemi ile önceliklendirilmesi ve ihtiyaçlara cevap verebilecek en iyi yazılım kriterlerinin kullanıcılar açısından belirlenmesi amaçlanmıștır. Araştırmada ISO/IEC TS 25011:2017 yazılım kalite modeli çerçevesinde yazılım hizmeti kalitesine ait değerlendirmeler AHP kullanılarak yapıldıktan sonra elde edilen bulgular, turizm ve konaklama ișletmelerine göre Otel Yönetim Sistemleri (OYS) yazılım hizmet kalitesi ile ilgili kriterlerin öncelik sıralamasını sunmaktadır. Ana Kriterlere bakıldığında sırasıyla Bilgi Teknolojileri Hizmeti Uyarlanabilirliği, Somutluk, Bilgi Teknoloji Servis Bakım Kolaylığı, Bilgi Teknoloji Servis Güvenilirliği, Kullanışlılık, Heveslilik, Güvenlik ve Uygunluk olarak bulunmuștur. Analiz sonuçları, turizm ve konaklama ișletmelerine yazılım hizmeti veren firmaların bu sonuçları dikkate alarak verdikleri hizmetlerin kalitesinde iyileştirme yapmaları adına yol gösterici olacağı düşünülmektedir.
\end{abstract}

\footnotetext{
${ }^{*}$ Corresponding Author,

E-mail: memre.guler@ikc.edu.tr (M. E. Güler)
} 


\section{1 | GİRIS}

Hızla gelişen teknoloji bilgiye erişimi kolaylaştırırken, sanal ortamda depolanan bu bilgilerin yönetimi için de çeşitli yöntemler, programlar geliştirilmektedir. Bilginin varlığı kendi başına güç olmadığı gibi, bilginin nasıl kullanılacağı da gücün elde edilmesinde önem teşkil etmektedir. Bilginin işlenmesi ve yönetilmesi üzerine oluşan teknolojiler geliştikçe işletmelerin bu alanda ihtiyaçları da gelişmelere paralel olarak artmaktadır. Bilgiyi temin etmede, küreselleşmeye bağlı olarak sınırların genişlemesiyle birlikte, işletmeler çerçevesinde rekabet de hız kazanmaktadır. Bilgiden en üst düzeyde yararlanmayı sağlamanın en verimli yolu ise bu bilgiyi işleyebilecek ve yönetimini sağlayabilecek bir bilgi yönetim sistemi oluşturmaktan geçmektedir. Bilgi yönetiminin önemli bir kavram haline gelmeye başlamasıyla beraber işletmeler bu alanda yatırımlar yapmaya başlamış ve örgütlerin içerisinde bilgi yönetimi ile ilgili birimler kurulmaya başlanmıştır.

Bilgilerin bir araya toplanması ve işlenmesi teknolojik gelişmelerle birlikte hızlı bir şekilde gerçekleşebilmektedir. Bilgi ve bilişim teknolojileri üretim, ticaret, eğitim ve hizmet gibi birden fazla alanda kullanılmaktadır. Bilișim teknolojilerinin gelişimi, işletmelerde hizmet kalitesini arttırmak ve müşteri memnuniyetini üst düzeylere çıkarmaktadır. $\mathrm{Bu}$ işletmelere turizm endüstrisi içerisinde bulunan konaklama işletmeleri de dâhildir. Bilişim teknolojilerinin kullanımı aracılığı ile rezervasyonlar, ödemeler, oda yönetimleri, kasa işlemleri gibi konaklama işletmelerine özgü birçok bölüm yönetilebilmektedir. $\mathrm{Bu}$ alanda hızla gelişen ve gelişmekte olan "otel yönetim sistemi" üreten birden fazla yazılım şirketi bulunmaktadır. $\mathrm{Bu}$ yazılım şirketlerinin sundukları otel yönetim sistemlerinden bazıları ücretsizken, bazıları da ücretlidir. Öte yandan yazılımların ücretsiz olan sürümlerinin kullanıcılarına vermiş olduğu destek ücretli olan sürümlere oranla daha kısıtlı olabilmektedir. Yazılıma ve bununla ilgili donanıma yapılacak yatırımların yanında yatırım sonrası alınacak destek hizmetinin kalitesi de ön plana çıkan önemli bir unsurdur.

Bu bağlamda, yapılan bu çalıșmada, ilk olarak bilgi ve bilgi yönetim sistemleri hakkında yapılan açıklamaların ardından otel yönetim sistemleri ve içerikleri hakkında bilgiler sunularak devamında otel işletmelerinin kullandıkları otel yönetim sistemleri kapsamında sunulan hizmet kalitesi ile ilgili önceliklerin belirlenmesine yönelik araştırma

bulguları ortaya konmuştur. Bu bağlamda Analitik Hiyerarşi Sürecinden yararlanılarak otel yönetim sistemlerinin hizmet kalitesi boyutlarının kullanıcılar açısından önceliklendirilmesi yapılmaya çalışılmıştır.
Bu sayede hem kullanıcıların otel yönetim sistemi ile ilgili aldıkları hizmet kalitesinin öncelikleri belirlenmiş ve bunun yanında hizmet sağlayıcıları açısından kullanıcı bakışına objektif değerlendirmelerle ulaşmaları sağlanmaya çalışılmıştır.

\section{2 | KAVRAMSAL ÇERÇEVE}

Bilgi yönetimi alanyazında farklı araştırmacılar tarafından farklı yönlerinden ele alınarak ulaşılmak istenen amaç doğrultusunda farklı biçimlerde tanımlanmaktadır. Bilgi yönetimi bilgiyi bir bütün olarak ele alarak her tür ve davranışını gözlem altında tutar (Şencan, 2013, s. 20).

Barutçugil'e (2002) göre bilgi yönetimi, organizasyonel amaçların daha etkin şekilde sağlanabilmesi için bireylere, takımlara ve organizasyonun tümüne bilginin kolektif ve sistematik olarak yaratılması, paylaşılması ve uygulanmasını mümkün kılan bir disiplindir. Şencan (2013, s. 21) ise bilgi yönetimini; hızlı bir şekilde kurumsal karar alınmasını sağlamak, iş ve çalışan personel performansını artırmak ve örgütsel verimliliğe katkı sağlamak amacıyla gerek duyulan her türlü bilginin üretimi, depolanması, örgüt içerisinde paylaşılması ve uygulanmasını kapsayan ve örgütlerde örtük durumda var olan bilginin açığa çıkarılmasını sağlayarak paylaşımını ve örgütte kullanımını sağlayan disiplinler arası bir bilim dalı olarak tanımlanır. Kısa bir tanımla bilgi yönetimi, organizasyonun amaçlarına yönelik olarak bilginin üretimi, dağıtımı, değerlendirilmesi ve ayrıca etkili biçimde kullanılmasıyla ilişkili tüm süreçlerin yönetilmesi anlamına gelmektedir (Zaim, 2005, s. 80).

Bilgi yönetiminin amaçları noktasında; bilgi yönetimini, bilgiyi bulma, anlama, kullanma ve değer yaratmak üzere kullanılan sistematik bir yaklaşım olarak tanımlayan Celep ve Çetin (2003, s. 25-32), bilgi yönetiminin temel amacl olarak örgütün çevresinde oluşan teknolojik ve bilimsel gelişmeler ile kavramsal gelişmelerden haberdar olunması ve bilgilerin örgüte yansıtılmasından söz etmektedir. Bunun yanı sıra, bilgi depolamasını sağlayarak bilgiye ulaşımı geliştirmek, bilgi ortamını arttırmak ve bir servet olarak bilgiyi yönetmek amaçlarını da sıralamaktadır. Bilgi yönetiminin temel amaçları Yeniçeri ve İnce (2005, s. 67-68) tarafından öğrenme eğrisini hızlandırmak, daha hızlı iyileștirme sağlamak, doğru bilginin doğru insanlara doğru zamanda ulaşmasını kolaylaştırmak, hızlandırılmış dönüşüme olanak sağlamak olarak sıralanmıştır. Bilgi yönetiminin temel amacı olarak ise, bilgi aktarımını teşvik etmek ve bilgi paylaşımını sağlamaktan söz etmektedirler. Zaim'e (2005) göre ise bilgi yönetiminin uygulanma amaçları arasında diğer açıklamalara benzer biçimde, örgütün sahip olduğu bilgi potansiyelinden maksimum düzeyde yararlanmak, bilgi varlıklarını en etkili biçimde 
kullanarak en yüksek verimi elde etmek yer almaktadir.

Bilgi yönetimi, örgütlerin varlığı ve devamlılığı konusunda büyük önem arz etmektedir. Celep ve Çetin'e (2003) göre üç temel etmen, bilgi yönetimini önemli kılar; rekabet artışı, müşteri taleplerinin değişikliğe uğraması ve iş çevresinin hızlı bir biçimde değişiyor olmasıdır. Zaim (2005, s. 97) ise bilgi yönetiminin öneminin artmasındaki en önemli unsurun teknolojik gelişmeler olduğunu belirtmektedir $\mathrm{Bu}$ kapsamda teknolojik etkinin ortaya çıkan üç yönünden söz etmektedir; bunlardan ilki enformasyon kaynaklarının artması, enformasyona ulaşımın kolaylaşması ve ucuzlamasıdır; ikinci yönünü üretim yapısı, tarzı ve ürün dönüşüm sürelerinin kısaltılmasıyken sonuncusunu ise bilgi yönetimi faaliyetlerinin etkinliğini artırmış olması oluşturmaktadır.

Bilgi yönetiminin örgütlere sağlayacağı yararlar dört temel maddede toplanabilecektir: (i) bilgi işçilerinin bilgi konusundaki farkındalığının artması, (ii) bilginin ulaşılabilirliği, (iii) bilginin kullanılabilirliği ve (iii) bilgi elde etmeye ilișkin etkin zamanlama. Bu yararlara ulaşmak ise bilgi sisteminin yapılandırılmasından bilgi işçilerinin yeteneklerine kadar değişebilen pek çok unsura bağlı olmaktadır (Offsey, 1997, s. 115).

\section{1| Konaklama İşletmelerinde Bilgi Yönetimi ve Otel Yönetim Sistemleri}

İşletmelerde sıklıkla kullanılan bilişim sistemlerinin genel olarak bütün bir işleyişe katkılar sağladığı düşünülmektedir. $\mathrm{Bu}$ düşünce ise akademik çalışmalar ile doğrulanmaktadır. Günümüz işletmelerinde yapılan harcamaların \%50 oranına yakınını bilgi teknolojileri oluşturmaktadır (Bruque ve Medina, 2002, s. 76).

Konaklama işletmelerinin de yoğun rekabet ortamında varlıklarının devamlılığını sağlayabilmeleri ve rekabet üstünlüğü elde edebilmelerinin büyük ölçüde bilgiyi toplama, depolama, yorumlama ve bu bilgiyi hızlı ve etkili bir biçimde kullanabilme yeteneklerine bağlı olduğundan söz etmek mümkündür. Doğru bilgiye doğru zamanda ulaşmak ve ulaşılan bilgiyi etkin bir biçimde kullanabilmek konaklama işletmelerinin karar verme mekanizmalarını hızlandırarak rekabet ortamında üstünlük elde etmelerine yardımcı olmaktadır.

Ham vd.'nin (2005) belirtmiş olduğu üzere bilgi teknolojileri sistemlerinin kullanılması, maliyetlerde azalma sağlamaktadır. Verimlilik ve gelirlerde artış otel sektöründe müşteri hizmetleri ve iş operasyonlarını geliştirerek sağlanmıştır. Son yıllarda araştırmacılar, performans veya verimlilikte bilgi teknolojilerinin kullanımının etkilerini belirlemek üzere çalışmalar yapmaktadırlar.
Gerçekleştirilmiş araştırmalarında çoğunda araştırmacılar, bilgi teknolojisi kullanımının etkilerini nicel ölçeklerle ortaya koymuşlardır ve bilgi teknolojisi yatırımı ile verimlilik ve performans arasında olumlu ilișkiler tespit etmişlerdir.

Otel işletmelerinde bilgi yönetimi müşteri hizmetlerinin arttırılması ve yönetim süreçlerinde etkinlik ve verimliliğin iyileștirilmesine odaklanmaktadır (Zhao, 1998, s. 288). Şekil 1'de gösterilen otel işletmelerinde bilgi yönetim sistemleri işleyişi kapsamında teknoloji, otel işletmelerinde bilgi yönetimini hızlandırmakta, ürün ve hizmetlerin sunulması için seçenek sunmakta ve karar alma süreçlerini hızlandırmaktadır. Turizm ișletmelerinin bir kolu olan otel işletmeleri emek ve sermaye yoğun işletmeler oldukları için teknolojinin bu kapsamda doğru ve etkin kullanımı işgücü maliyetini önemli ölçüde düşürebilmektedir. Aynı zamanda müşteri hizmetleri alanında da görülebilen teknoloji, örneğin otomatik giriş ve çıkış işlemleri, güvenlik, kat hizmetleri ya da en güncel olarak elektronik danışma hizmetleri alanlarında görülebilmektedir.

\section{Şekil 1: Otel Yönetim Sistemlerinin İşleyiş Şeması}

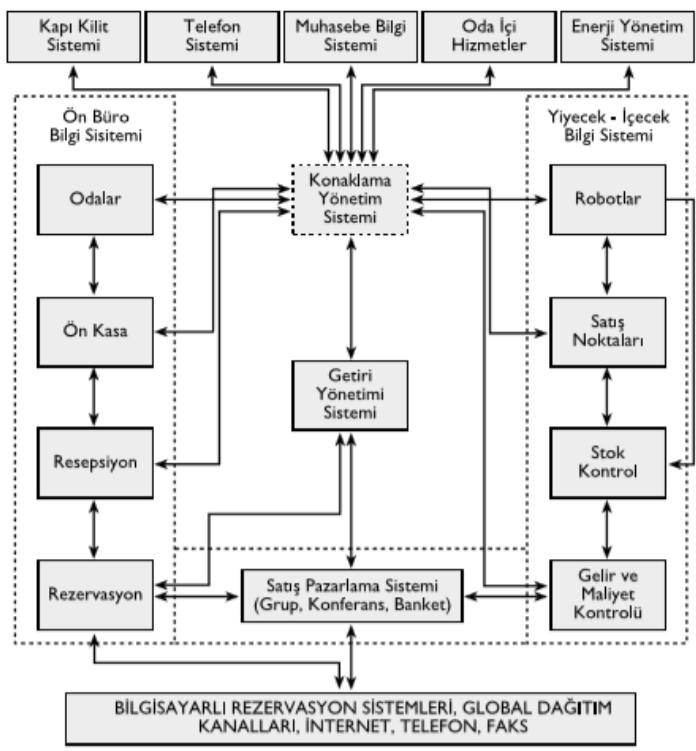

Kaynak: Emeksiz, (2002) s. 36

Met ve Erdem'in (2006, s. 68-69) de belirtmiş olduğu gibi, otel işletmelerinde teknoloji son yıllarda kullanılan elektronik danışma hizmetinin yanı sıra, akıllı otel odalarının yaratılması ve tasarlanmasında da geniş ölçüde kullanılmaktadır. Elektronik danışma hizmetinde müşteriler yerel hava koşullarından, ziyaret yerlerini seçme ve tur haritası çıkarmaya kadar ihtiyaçları olan geçerli ve doğru bilgiye ulaşabilirken, akıllı otel odaları sayesinde de konakladıkları odalarına ilişkin sıcaklık, ışıklar ve ses, hava temizliği gibi ihtiyaçlarını bireysel olarak kontrol edebilmektelerdir. Ayrıca müşteri odalarında bulunan iletişim portalları turistlerin dış dünya ile iletişimlerinde çok önemli bir araç görevi 
görmektedir ve teknoloji temelli hizmetleri sunan otel işletmeleri uluslararası hizmet alanında da önemli bir rekabet üstünlüğü elde edebilmektedir.

Literatür incelendiğinde otellerin bilgi teknolojileri ile ilgili almış oldukları hizmetin kalitesini ISO standartlarına göre ölçen bir çalışmaya rastlanılmamakla birlikte yapılan çalıșmaların; teknolojinin otellere etkileri (Sheldon, 1983), otellerin bilgi yönetim sistemi kullanma durumları (Law ve Jogaratnam, 2005), kullanilan ön büro yönetim sistemi, müşteri ilişkileri yönetim sistemi, tedarik zinciri yönetim sistemi gibi bileşenlerin entegrasyonu (Xiang vd., 2003), ERP sistemlerinin otel işletmelerine uygulanması (Vienna vd., 2014) ile ilgili çalışmalara rastlanırken teknoloji seçimi ile ilgili olarak otel işletmelerine yönelik çok kriterli karar verme teknikleri kullanılarak bir otel yönetim sistemi seçimi ya da buna ilişkin hizmet kalitesi standartlarının önceliklendirilmesi ile ilgili bir çalışmaya rastlanmamıştır. $\mathrm{Bu}$ durum çalışmanın sonuçlarının tartışılmasında hem bir kısıt oluştururken aynı zamanda çalışmanın özgünlügüne de vurgu yapmaktadır.

\section{3 | METODOLOJí}

Günümüzde bilgisayar teknolojileri ve internet her alanda olduğu gibi turizm sektöründe de yoğun olarak kullanılmaktadır. Kurumsal konaklama işletmelerinde tüm iş süreçleri otel yönetim sistemleri üzerinden yürütülmektedir. Bu sistemlerin sahip olduğu özellikler işletmelerin verimliliği ve sürdürülebilirliği gibi kriterleri etkilemektedir. $\mathrm{Bu}$ sebeple otel yönetim sistemleri konaklama işletmeleri için son derece önem arz etmektedir. Kullanılan yazılımların sahip olduğu özellikler iş süreçlerini etkilemektedir.

Bilgi yönetim sistemlerinin otellerde kullanılan diğer yazılımlar ile birlikte çalışabilirliği çok önemlidir ve bütünleşik çalışan sistemlerin birlikte değerlendirilmesi gerekmektedir. $\mathrm{Bu}$ bağlamda otellerde kullanılan bilgi yönetim sistemlerinin kalitesini, sunulan hizmetin kalitesini etkilediğini söylemek mümkündür. İlgili alanda hizmet sağlayıcılar ya da otellerin kendi bilgi teknolojileri ekipleri tarafindan sunulan bu hizmetler sistemin satın alma aşamasından başlayarak, kurulumu ve kurulum sonrasında yapılan önleyici bakım, düzeltici bakım, onarım gibi faaliyetleri içermektedir. $\mathrm{Bu}$ faaliyetler yatırım maliyeti oldukça önemli bir kalemi oluşturan otel yönetim sistemleri için belirli standartlarda yapılmaktadır. Yapılan bu çalışmada ISO/IEC TS 25011:2017 SQuaRE dokümanında belirtilen yazılım hizmet kalitesi standartlarının kullanıcılar açısından öncelik durumları belirlenmeye çalışılacaktır. Böylelikle hizmet sağlayıcıların verecekleri hizmet için hangi standarda daha fazla önem vermesi ile ilgili karar problemine katkı sağlamak amaçlanmaktadır.

\section{1 | Araștırmanın Kapsamı}

Çalışma kapsamında, ISO/IEC TS 25011:2017 (Enformasyon Teknolojileri- Sistem ve Yazılım Kalite Gereksinimleri ve Değerlendirme (SQuaRE) - Servis Kalite Modelleri) dokümanında yer alan "IT Servisleri Kalite Modeli"nde belirtilen hizmet kalitesi özellikleri ve alt kriterleri baz alınarak oluşturulan soru formuyla, İzmir il merkezindeki 5 yıldızlı otellerde bilgi sistemleri kullanıcıları ile görüşmeler yapılarak veriler toplanmıştır. Toplamda 23 kişiyle yapılan görüşmeler otel işletmelerini ziyaret ederek yüz yüze görüşmelerle gerçekleşmiştir. Bunun yanı sıra Travel Turkey Fuarı kapsamında yapılan ziyaretlerden de veriler elde edilmiștir. Araștırmanın katılımcı sayısının anket çalışmalarında olduğu gibi ana kütleyi yansıtacak büyüklükte olmasına AHP yönteminde gerek duyulmamaktadır (Tüzemen ve Özdağoğlu, 2007; 218). Katılımcılarla yapılan görüşmelerde İzmir il merkezinde faaliyet gösteren 5 yıldızlı otel işletmelerinin bilgi teknolojileri ile ilgili çalışanlarına ulaşılmaya çalışılmıştır. İzmir ilinde bulunan 5 yıldızlı konaklama işletmeleri kurumsal yapıda ve zincir otel işletmeleridir. Kullanmış oldukları yazılımlar ve aldıkları hizmetler de bu kapsamda kurumsal bir yapı içerisindedir. $\mathrm{Bu}$ kapsamda, Otellerin kullanmış oldukları otel bilgi yönetim sistemlerinden aldıkları hizmetin ISO/IEC TS 25011:2017 dokümanında belirtilmiş olan kriterlerden hangisine daha fazla önem verdikleri saptanmaya çalışılmıştır.

\section{2 | Araştırmanın Yöntemi}

Çalışmada, ISO (www.iso.org) (International Organization for Standartization) web sayfası üzerinden enformasyon teknolojileri, sistem ve yazılım kalite gereksinimleri için yayınlanmış olan en güncel doküman olan ISO/IEC TS 25011:2017 dokümanından belirtilmiş olan kalite karakteristikleri ve alt karakteristikleri doğrultusunda bir soru formu hazırlanmıştır. İlgili dokümanda belirtilmiş olan her kalite karakteristiği için katılımcılardan ikili karşılaştırma matrisleri yardımıyla veriler elde edilmiştir. Bu veriler daha sonra Analitik Hiyerarşi Süreci (AHP) prosedürü ile hizmet kalitesi kriterlerinin öncelik bilgileri ile ilgili bulgulara ulaşmayı sağlamıştır. Araştırma için ISO/IEC TS 25011:2017 dokümanına göre hazırlanan hiyerarşik model Şekil 2'de gösterilmektedir. 
Şekil 2: Araştırmanın Hiyerarşik Modeli

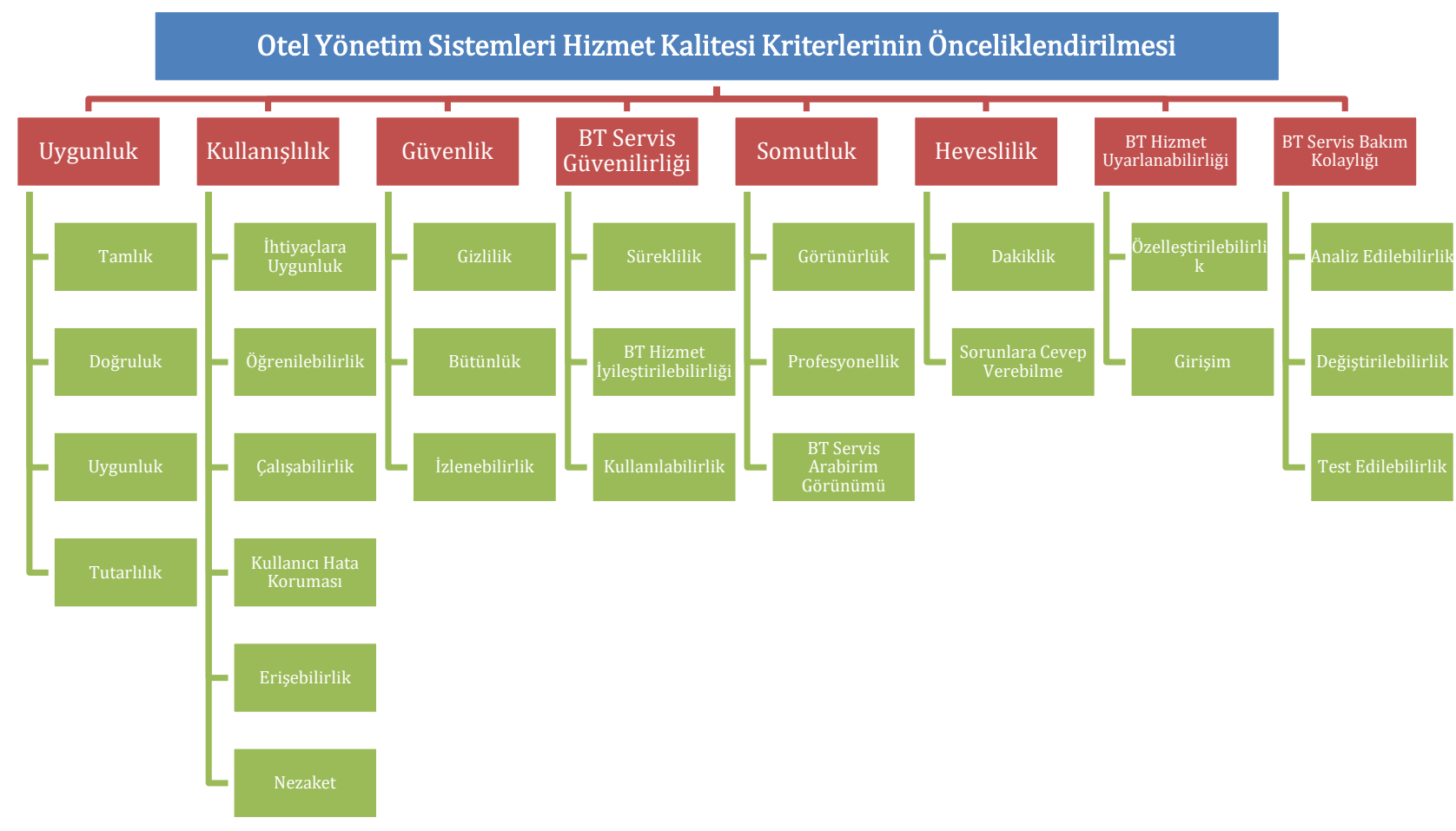

$\mathrm{Bu}$ bağlamda, çalışmanın amacına ulaşmak için kullanılan AHP yöntemi ilk olarak Thomas L. Saaty tarafından 1970 yıllarında silah ticareti, kaynakların verimliliğini belirleme ve varlık tahsis edilmesine karar verme yolu amaciyla geliştirilmiştir (Saaty, 1988; Saaty, 1990). Bu yöntemde, hiyerarşik bir yapı oluştururken ilk olarak sistemin meydana gelmesini sağlayan kriterlerin birbirleri arasındaki işlevsellik ilişkileri ve bu ilişkilerin sistemin tümüne olan etkisinin analizi ortaya çıkarılmakta ve kontrol altında olan ya da olmayan sistem bileşenlerinin özelliklerine göre gruplandırılır (Melvin, 2012; Çakır, 2012; Çakır, 2008). AHP insan doğasına ve zekâsına göre oluşturulmuştur. Yöntem olarak, yarglar ve kişisel değerlendirmelerden oluşan yöntemler kullanılmaktadır. Sonuç itibari ile AHP, karar kriterlerini hiyerarşik bir yapı içerisinde önceliklerini belirlemek ve oluşturmak için bireysel izlenimleri temel almaktadır (Bitarafan vd., 2015, s. 137-148).

AHP'nin temel olarak üç aşaması şu şekilde anlatılabilir(Oğuzlar, 2007, s. 122-134).

1. Aşamada karar hiyerarşisi oluşturulur.

2. Aşamada ikili karşılaştırma matrisleri oluşturulur.

3. Aşamada karşılaştırılan her ölçütün önemleri tespit edilir.

İkili karşılaștırma matrisinde kriterler birbirleri ile karşılaştırılır. Faktörler ikişerli olarak ele alınır ve her biri hakkında fikir edinmeye olanak veren bir yöntemdir.
Örnek olarak A ikili karşılaştırma matrisi aşağıda olduğu gibi gösterilebilir.

$$
A_{i j}=\left[\begin{array}{ccccc}
1 & a_{21} & a_{31} & \cdots & a_{n 1} \\
1 / a_{21} & 1 & a_{32} & \cdots & a_{n 2} \\
1 / a_{31} & 1 / a_{32} & 1 & \cdots & a_{n 3} \\
\vdots & \vdots & \vdots & \ddots & \vdots \\
1 / a_{n 1} & 1 / a_{n 2} & 1 / a_{n 3} & \cdots & 1
\end{array}\right]_{n \infty 21}
$$

Kaynak: Ömürbek vd., 2015, s. 21

\section{Önem Vektörünün HesaplanmasI}

Önem vektörünü hesaplayabilmek için ikili karşılaştırma matrisinden yararlanılmaktadır. (Yaralığlu, 2004; Samut, 2014, s. 60)

$$
w_{i}=\frac{\sum_{j=1}^{n} a_{i j} w_{j}}{n}
$$

\section{Tutarlılık Oranının Hesaplanması}

Yapılan karşılaştırmaların birbirileri arasında tutarlı bir ilişki olup olmadığının kontrol edildiği aşamadır. $\mathrm{Bu}$ oran "CR" harfleri ile gösterilmektedir. Bu değer 0,10'dan düşük ise değerlerin tutarlı olduğu ifade edilir. Aşağıda bulunan formül ile tutarlılık oranı belirlenmektedir. 


$$
C R=\frac{C I}{R I} ; \quad C I=\frac{\lambda \max -n}{n-1} ; \quad C R=\frac{\lambda \max -n}{(n-1) * R I}
$$

Formül üzerinde bulunan simgelerden " $\lambda$ max" en büyük özdeğeri. " $n$ " ise kriter sayısını göstermektedir. Araştırmanın Bulguları

Verilerin işlenmesinde MS Excel Yazılımı kullanılmıştır. Bu başlık altında demografik bulgular ve AHP yöntemine göre yapılan hesaplamaların sonucu elde edilen bulgular sunulmuştur.

Tablo 1: Demografik Bilgiler

\begin{tabular}{|l|l|l|}
\hline \multirow{4}{*}{ Cinsiyet } & Erkek & $\% 37,5$ \\
\cline { 2 - 3 } & Kadın & $\% 62,5$ \\
\hline \multirow{5}{*}{ Yaş } & $18-25$ & $\% 25,0$ \\
\cline { 2 - 3 } & $26-35$ & $\% 37,5$ \\
\cline { 2 - 3 } & $36-45$ & $\% 25,0$ \\
\cline { 2 - 3 } & $46-55$ & $\% 8,3$ \\
\cline { 2 - 3 } & 56 ve üstü & $\% 4,2$ \\
\hline \multirow{5}{*}{ İşitim Deneyimi } & Lisans & $\% 75,0$ \\
\cline { 2 - 3 } & Yüksek Lisans & $\% 12,5$ \\
\cline { 2 - 3 } & Doktora & $\% 12,5$ \\
\hline & 1 yıldan az & $\% 12,6$ \\
\cline { 2 - 3 } & 1-5 yıl & $\% 20,8$ \\
\cline { 2 - 3 } & 6-10 yıl & $\% 20,8$ \\
\cline { 2 - 3 } & 11 ve daha fazla & $\% 45,8$ \\
\hline
\end{tabular}

Değerlendirmeye katılan 23 kişinin demografik yapıları incelendiğinde $\% 62,5$ oranında kadın, \%37,5 oranında erkek olduğu, en yoğun yaş aralığının 26-35 arasında olduğu ayrıca bütün katılımclların asgari lisans düzeyine sahip olduğu görülmektedir.

Demografik bulgulardan sonra toplanan verilerle çalışmanın amacına ulaşmak için Analitik Hiyerarşi Süreci ile elde edilmiş bulgular Microsoft Excel Veri İşleme Yazılımı ile hesaplanarak hazırlanmıştır.

\section{Ana Kriterlere İlisskin Bulgular}

Hiyerarşik modelde belirtilmiş olan ana kriterlere ilişkin açıklamaları aşağıdaki şekilde sıralamak mümkün olacaktır:

Uygunluk (K1): Bir BT hizmetinin belirtilen kullanım koşullarında kullanıldığında önceden belirlenmiş gereksinimleri karşılama derecesidir.

Kullanışlılık (K2): BT hizmetinin gereksinimleri karşılama derecesidir.

Güvenlik (K3): Teknoloji altyapısının güvenlik tehditlerine karşı korunmasını destekleyen kontroller bütünüdür.

BT Servis Güvenilirliği (K4): BT servisinin tutarlı ve istikrarlı servis sonuçları sağladığı derecedir.

Somutluk (K5): BT hizmetinin somut yönlerinin hizmeti etkili bir șekilde iletme ve destekleme derecesidir.

Heveslilik (K6): BT hizmetinin zamanında sonuç ve cevap verme derecesidir.

BT Hizmeti Uyarlanabilirliği (K7): BT hizmetinin süreç içinde ortaya çlkan yeni düzenleme gereksinimlerini karşılayacak şekilde yapılandırılmasını ifade eder.

BT Servis Bakım Kolaylı̆̆ (K8): IT servisinin, servis sağlayıcı tarafından sunulan etkililik ve verimlilik derecesidir. 
Tablo 2: Hizmet Kalitesi Ana Kriterlerine Göre İkili Karşllaştırma Tablosu

\begin{tabular}{|l|l|l|l|l|l|l|l|l|}
\hline & $\mathrm{K} 1$ & $\mathrm{~K} 2$ & $\mathrm{~K} 3$ & $\mathrm{~K} 4$ & $\mathrm{~K} 5$ & $\mathrm{~K} 6$ & $\mathrm{~K} 7$ & $\mathrm{~K} 8$ \\
\hline $\mathrm{K} 1$ & 1,000000 & 1,027708 & 0,618705 & 0,437992 & 0,741009 & 0,616971 & 0,482754 & 0,487963 \\
\hline K2 & 0,973039 & 1,000000 & 0,741236 & 0,649844 & 1,538159 & 1,535432 & 1,10433 & 0,955051 \\
\hline K3 & 1,616280 & 1,349098 & 1,000000 & 0,896808 & 0,650128 & 0,962803 & 0,325593 & 0,366787 \\
\hline K4 & 2,283146 & 1,538832 & 1,115066 & 1,000000 & 0,770331 & 1,166526 & 0,92465 & 0,70374 \\
\hline K5 & 1,349512 & 0,650128 & 1,538159 & 1,298144 & 1,000000 & 1,827673 & 0,690518 & 2,250475 \\
\hline K6 & 1,620821 & 0,651283 & 1,038634 & 0,857246 & 0,547144 & 1,000000 & 0,752963 & 0,68761 \\
\hline K7 & 2,071448 & 0,905527 & 3,071323 & 1,081490 & 1,448187 & 1,328087 & 1,000000 & 0,928155 \\
\hline K8 & 2,049334 & 1,047065 & 2,726381 & 1,420979 & 0,444351 & 1,454312 & 1,077406 & 1,000000 \\
\hline Toplam & 12,963580 & 8,169639 & 11,849503 & 7,642503 & 7,139308 & 9,891803 & 6,358214 & 7,379781 \\
\hline
\end{tabular}

Tablo 2'de Hiyerarşinin birinci seviyesindeki ana kriterler için değerlendirmeye katılan kişilerden elde edilen veriler doğrultusunda oluşturulan karşılaştırma tablosu hazırlanmıștır. $\mathrm{Bu}$ tablo hazırlanırken katılımcıların verdikleri yanıtların geometrik ortalaması alınmıştır. Bu tabloya göre yapılan hesaplamalara göre her bir hücrenin kendi sütun toplamına bölünmesiyle Tablo 3 hazırlanmıştır.

Tablo 3: Hizmet Kalitesi Ana Kriterlerine Göre Ağırlıklar

\begin{tabular}{|l|l|l|l|l|l|l|l|l|l|}
\hline & $\mathrm{K} 1$ & $\mathrm{~K} 2$ & $\mathrm{~K} 3$ & $\mathrm{~K} 4$ & $\mathrm{~K} 5$ & $\mathrm{~K} 6$ & $\mathrm{~K} 7$ & $\mathrm{~K} 8$ & $\begin{array}{l}\text { Önem } \\
\text { Seviyesi }\end{array}$ \\
\hline $\mathrm{K} 1$ & 0,077139 & 0,125796 & 0,052214 & 0,057310 & 0,103793 & 0,062372 & 0,075926 & 0,066122 & 0,077584 \\
\hline $\mathrm{K} 2$ & 0,075059 & 0,122404 & 0,062554 & 0,085030 & 0,215449 & 0,155223 & 0,173686 & 0,129414 & 0,127353 \\
\hline K3 & 0,124679 & 0,165136 & 0,084392 & 0,117345 & 0,091063 & 0,097333 & 0,051208 & 0,049702 & 0,097607 \\
\hline K4 & 0,176120 & 0,188360 & 0,094102 & 0,130847 & 0,107900 & 0,117929 & 0,145426 & 0,095361 & 0,132006 \\
\hline K5 & 0,104100 & 0,079579 & 0,129808 & 0,169858 & 0,140070 & 0,184766 & 0,108603 & 0,304951 & 0,152717 \\
\hline K6 & 0,125029 & 0,079720 & 0,087652 & 0,112168 & 0,076638 & 0,101094 & 0,118424 & 0,093175 & 0,099237 \\
\hline K7 & 0,159790 & 0,110840 & 0,259194 & 0,141510 & 0,202847 & 0,134261 & 0,157277 & 0,125770 & 0,161436 \\
\hline K8 & 0,158084 & 0,128165 & 0,230084 & 0,185931 & 0,062240 & 0,147022 & 0,169451 & 0,135505 & 0,152060 \\
\hline & & & & & & & & & 1,000000 \\
\hline
\end{tabular}

$C I=0,060591096$

$C R=0,042972$

Önem seviyesi sütunundaki değerler, uygunluk, kullanıșlılık, güvenlik, BT servis güvenliği, somutluk, heveslilik, BT hizmeti uygulanabilirliği sütunlarındaki değerlerin ortalamasıdır. CR 0,042972 değeri 0,10'den küçük olması (Yaralığlu, 2004; 29); Tablo 3'deki ikili karşılaştırma tablonun tutarlı olduğunu göstermektedir. Önem düzeyi tablosuna göre ana kriterlerden BT hizmeti uygulanabilirliği $(0,161436)$ en önemli kriterdir. Bu kriterin ardından katılımcılar tarafindan belirlenen önem sirası; Somutluk $(0,152717)$, BT Servis Bakım Kolaylığı $(0,15206)$, BT Servis Güvenilirliği $(0,132006)$, Kullanışlılık 
$(0,127353), \quad$ Heveslilik $(0,099237), \quad$ Güvenlik $(0,097607)$ ve uygunluk $(0,077584)$ olarak belirlenmiştir.

\section{3 | Alt Kriterlere İlişkin Bulgular}

Uygunluk ana kriterinin alt kriterlerine göre yapılan ve alt kriterlerinin ağırlıklarını gösteren sonuç tablosu Tablo 4'te gösterilmektedir. Alt kriterlere ilişkin açıklamalar aşağıda verilmiştir:
Tamllk (U1): Bir BT hizmetinin kullanıcı tarafindan belirtilen tüm hedefleri, amaçları ve verileri destekleme derecesidir.

Doğruluk (U2): Bir BT hizmeti ile elde edilen veriler ile doğru sonuçları üretme derecesidir.

Uygunluk (U3): BT servisinin kullanıcı için uygun sonuçları sağlama derecesidir.

Tutarlılık (U4): Tekrarlanan işlemlerde aynı ve tutarlı sonuçların sağlanmasıdır.

Tablo 4: Uygunluk Kriterine göre Ağırlıkların Belirlenmesi

\begin{tabular}{|l|l|l|l|l|l|}
\hline & U1 & U2 & U3 & U4 & Onnem Seviyesi \\
\hline U1 & 0,193629 & 0,132341 & 0,275253 & 0,197833 & $\mathbf{0 , 1 9 9 7 6 4}$ \\
\hline U2 & 0,344172 & 0,235233 & 0,193991 & 0,220892 & $\mathbf{0 , 2 4 8 5 7 2}$ \\
\hline U3 & 0,203762 & 0,351237 & 0,289658 & 0,317229 & $\mathbf{0 , 2 9 0 4 7 1}$ \\
\hline $\mathbf{U} 4$ & 0,258436 & 0,281189 & 0,241098 & 0,264047 & $\mathbf{0 , 2 6 1 1 9 2}$ \\
\hline & & & & & $\mathbf{1 , 0 0 0 0 0 0}$ \\
\hline
\end{tabular}

$C I=0,026451 \quad C R=0,02939$

Önem Düzeyi olarak belirtilen sütundaki değerler Tamlık, Doğruluk, Uygunluk ve Tutarlılık sütunlarının ortalama değerleridir. CR değerinin 0,1 'den küçük bir faktörün Uygunluk $(0,290471)$ olduğu saptanmıștır. En önemli ikici faktör ise Tutarlılıktır $(0,261192)$. Doğruluk faktörü $(0,248572)$ üçüncü sıraya sahipken en az önem düzeyine sahip faktör ise Tamlıktır $(0,199764)$.

Kullanışllık ana kriterinin alt kriterlerine göre yapılan ve alt kriterlerinin ağırlıklarını gösteren sonuç tablosu Tablo 5 'te gösterilmektedir. Alt kriterlere ilişkin bilgiler ise aşağıda verilmiştir:

İhtiyaçlara Uygunluk (KU1): Bir BT servisinin gereksinimler için uygun olup olmadığının anlaşılabileceği derecedir. Hizmetin uygunluğu, bu hizmetlerin ilk izlenimlerinden ve / veya ilgili herhangi bir belgeden tanınacaktır. Hizmetin detayları dokümantasyon, sunum veya tanıtım malzemeleri gibi potansiyel araçlarla açıklanabilir.

öğrenilebilirlik (KU2): Bir BT hizmetinin belirli bir süre kullanımında; etkililik, verimlilik, riskten değer olması tutarlı olduğunu gösterir. Uygunluk kriterlerinde en önemli

korunma ve memnuniyet seviyesini elde etmek için kullanıcılar tarafından öğrenilme derecesini ifade eder.

Çalışabilirlik (KU3): BT servisinin çalıştırılmasını ve kontrolünü kolaylaştıran özelliklere sahip olma derecesidir.

Kullanıcı Hata Koruması (KU4): BT servisinin kullanıcıları hata yapmalarına karşı korumasıdır.

Erişilebilirlik (KU5): Belirli bir kullanım bağlamında belirli bir hedefe ulaşmak için belirli özelliklere sahip kişiler tarafından hizmetin ne ölçüde kullanılabileceğini ifade eder. Özellikler arasında yaş, görme, işitme ve fiziksel hareketlilik gibi engel durumları vardır.

Nezaket (KU6): Sağlanan BT hizmetinin kibar, saygllı ve dostane bir şekilde verilme derecesidir. 
Tablo 5: Kullanışlılık Kriterine göre Ağırlıkların Belirlenmesi

\begin{tabular}{|l|l|l|l|l|l|l|l|}
\hline & KU1 & KU2 & KU3 & KU4 & KU5 & KU6 & Önem Seviyesi \\
\hline KU1 & 0,145560 & 0,207872 & 0,213548 & 0,144058 & 0,103941 & 0,092904 & $\mathbf{0 , 1 5 1 3 1 4}$ \\
\hline KU2 & 0,115986 & 0,165638 & 0,165011 & 0,237938 & 0,140028 & 0,165121 & $\mathbf{0 , 1 6 4 9 5 4}$ \\
\hline KU3 & 0,111078 & 0,163579 & 0,162960 & 0,201753 & 0,176939 & 0,137882 & $\mathbf{0 , 1 5 9 0 3 2}$ \\
\hline KU4 & 0,208435 & 0,143602 & 0,166619 & 0,206284 & 0,329198 & 0,226762 & $\mathbf{0 , 2 1 3 4 8 4}$ \\
\hline KU5 & 0,249882 & 0,211069 & 0,164337 & 0,111811 & 0,178435 & 0,269429 & $\mathbf{0 , 1 9 7 4 9 4}$ \\
\hline KU6 & 0,169058 & 0,108239 & 0,127526 & 0,098157 & 0,071460 & 0,107901 & $\mathbf{0 , 1 1 3 7 2 3}$ \\
\hline & & & & & & & $\mathbf{1 , 0 0 0 0 0 0}$ \\
\hline
\end{tabular}

$C I=0,040187 \quad C R=0,032408574$

Tablo 5'deki İhtiyaçlara Uygunluk, Öğrenilebilirlik, İşletilebilme, Kullanıcı Hatası Önleme, Erişilebilirlik ve Nezaket kriterleri için CI ve CR değerleri 0,1'den küçük olduğu için tablonun tutarlı olduğu kabul edilmektedir. Buna göre Kullanıcı Hatası Önlemenin $(0,213484)$ en önemli unsur olduğu görülmektedir. Erişilebilirlik $(0,197494)$ ikinci derecede önemli iken diğer unsurlar ise önem düzeyine göre Öğrenilebilirlik $(0,164954)$, İşletilebilme $(0,159032)$, İhtiyaçlara Uygunluk $(0,151314)$ ve Nezaket $(0,113723)$ şeklinde sıralanmaktadır.
Güvenlik ana kriterinin alt kriterlerine göre yapılan ve alt kriterlerinin ağırlıklarını gösteren sonuç tablosu Tablo 6'da gösterilmektedir. Alt kriterlere ilişkin bilgiler ise aşağıda verilmiştir:

Gizlilik (G1): BT servisinin verilere yalnızca erişim yetkisi verilen kişiler için erişilebilir olmasını sağlama derecesidir.

Bütünlük (G2): BT hizmetinin verilerin yetkisiz erişimini veya değiştirilmesini önleme derecesidir.

İzlenebilirlik (G3): BT hizmetinin çlktılarının kullanıcılar tarafından izlenebilme derecesini ifade eder.

Tablo 6: Güvenlik Kriterine göre Ağırlıkların Belirlenmesi

\begin{tabular}{|l|l|l|l|l|}
\hline & G1 & G2 & G3 & Önem Seviyesi \\
\hline G1 & 0,303427 & 0,352063 & 0,257654 & $\mathbf{0 , 3 0 4 3 8 1}$ \\
\hline G2 & 0,314147 & 0,364501 & 0,417611 & $\mathbf{0 , 3 6 5 4 1 9}$ \\
\hline G3 & 0,382426 & 0,283436 & 0,324735 & $\mathbf{0 , 3 3 0 1 9 9}$ \\
\hline & & & & $\mathbf{1 , 0 0 0 0 0 0}$ \\
\hline
\end{tabular}

$C I=0,011182 \quad C R=0,01928$

CR değerinin 0,1'den küçük olması tutarlılığına kanıttır. Buna göre en önemli alt kriter Bütünlük $(0,365419)$ olarak belirlenmiştir. Bunu sırasıyla İzlenebilirlik $(0,330199)$ ve Gizlilik (0,304381) izlemektedir

BT Servis Güvenilirliği ana kriterinin alt kriterlerine göre yapılan ve alt kriterlerinin ağırlıklarını gösteren sonuç tablosu Tablo 7'de gösterilmektedir. Alt kriterlere ilişkin bilgiler ise aşağıda verilmiştir:

Süreklilik (SG1): BT hizmetinin öngörülen tüm şartlar altında verilme derecesidir.

BT Hizmeti İyileştirilebilirliği (SG2): Gereksinimler doğrultusunda sistemsel düzenlemeler yapılabilmesi ve iş süreçlerine sistemsel uygunluk kazandırılmasını ifade eder. 
Kullanılabilirlik (SG3): BT hizmetinin kullanıcılar için ne derece uygun olduğunun belirlenebilmesini ifade eder.

Tablo 7: BT Servis Güvenilirliği Kriterine göre Ağırlıkların Belirlenmesi

\begin{tabular}{|l|l|l|l|l|}
\hline & SG1 & SG2 & SG3 & Önem Seviyesi \\
\hline SG1 & 0,327931 & 0,331927 & 0,324888 & $\mathbf{0 , 3 2 8 2 4 9}$ \\
\hline SG2 & 0,288848 & 0,292367 & 0,295447 & $\mathbf{0 , 2 9 2 2 2 1}$ \\
\hline SG3 & 0,383220 & 0,375706 & 0,379664 & $\mathbf{0 , 3 7 9 5 3 0}$ \\
\hline & & & & $\mathbf{1 , 0 0 0 0 0 0}$ \\
\hline
\end{tabular}

$C I=0,005056576 \quad C R=0,008718234$

Tablo 7'de Önem seviyesi sütununda yer alan Süreklilik, BT Hizmeti İyileștirilebilirliği ve Kullanılabilirlik kriterlerinin 0,1'den küçük olan CR değeri ile Tablonun tutarlılığın sağladığı görülmektedir. elde edilen değerlere göre en önemli unsur Kullanılabilirliktir (0,379530). İkinci olan Süreklilik (0,328249) unsurunu BT Hizmeti İyileştirilebilirliği $(0,292221)$ izlemektedir.

Somutluk ana kriterinin alt kriterlerine göre yapılan ve alt kriterlerinin ağırlıklarını gösteren sonuç tablosu Tablo 8'de gösterilmektedir. Alt kriterlere ilişkin bilgiler ise aşağıda verilmiştir:

Görünürlük (S1): Kullanıcıların BT hizmetinin özellikleri ile ilerleme sağlayabilecekleri derecedir.

Profesyonellik (S2): BT hizmetinin, uygun eğitim, beceri, uzmanlık ve yeterliliğe dayandığı derecedir.

BT Servis Arabirimi Görünümü (S3): Hizmet arayüzlerinin, kullanıcı için hoș ve tatmin edici bir görünüme veya diğer fiziksel özelliklere sahip olma derecesidir.

Tablo 8: Somutluk Kriterine göre Ağırlıkların Belirlenmesi

\begin{tabular}{|l|l|l|l|l|}
\hline & S1 & S2 & S3 & Önem Seviyesi \\
\hline S1 & 0,316421 & 0,277552 & 0,385861 & $\mathbf{0 , 3 2 6 6 1 1}$ \\
\hline S2 & 0,463182 & 0,406285 & 0,345375 & $\mathbf{0 , 4 0 4 9 4 7}$ \\
\hline S3 & 0,220397 & 0,316163 & 0,268764 & $\mathbf{0 , 2 6 8 4 4 1}$ \\
\hline & & & & $\mathbf{1 , 0 0 0 0 0 0}$ \\
\hline
\end{tabular}

\section{$C I=0,013475573 \quad C R=0,023233747$}

Somutluk ana kriterinin alt kriterleri olan Görünürlük, Profesyonellik ve BT Servis Arabirimi Görünümüne göre karşılaştırma yapılmış ve önem düzeylerini saptayabilmek için ağırlıklandırılmış değerler Tablo 8'deki gibi elde edilmiștir. Tablo 13'ün önem seviyesi sütununda yer alan Görünürlük, Profesyonellik ve BT Servis Arabirimi Görünümü kriterlerinin CR değeri 0,10 'den küçük olduğu için tablo tutarlıdır. Bu verilere göre Profesyonellik $(0,404947)$ en önemli unsurken diğer unsurlar sırası ile Görünürlük $(0,326611)$ ve BT Servis Arabirimi Görünümüdür $(0,268441)$.
Heveslilik ana kriterinin alt kriterlerine göre yapılan ve alt kriterlerinin ağırlıklarını gösteren sonuç tablosu Tablo 9'da gösterilmektedir. Alt kriterlere ilişkin bilgiler ise aşağıda verilmiştir:

Dakiklik (H1): Bir BT servisinin sınırlandırılmış zaman içinde sonuçlar sunma derecesidir.

Sorunlara Cevap Verebilme (H2): BT hizmetlerinin derhal kullanıcı taleplerine cevap verme derecesini ifade eder. Acil hizmet sunma derecesi bu nitelik alt özelliğinde de ele alınmaktadır. 
Tablo 9: Heveslilik Kriterine göre Ağırlıkların Belirlenmesi

\begin{tabular}{|l|l|l|l|}
\hline & $\mathrm{H} 1$ & $\mathrm{H} 2$ & Önem Seviyesi \\
\hline $\mathrm{H} 1$ & 0,434552 & 0,434552 & $\mathbf{0 , 4 3 4 5 5 2}$ \\
\hline $\mathrm{H} 2$ & 0,565448 & 0,565448 & $\mathbf{0 , 5 6 5 4 4 8}$ \\
\hline & & & 1,000000 \\
\hline
\end{tabular}

Elde edilen bulgulara göre katılımcılar tarafından belirlenen en önemli unsur Sorulara Cevap verebilmedir (0,565448). Dakiklik $(0,434552)$ ise ikinci önem seviyesine sahip bir unsur olarak belirlenmiștir.

BT Hizmeti Uyarlanabilirliği ana kriterinin alt kriterlerine göre yapılan ve alt kriterlerinin ağırlıklarını gösteren sonuç tablosu Tablo 10'da gösterilmektedir. Alt kriterlere ilişkin bilgiler ise aşağıda verilmiştir:

Özelleştirilebilirlik (HU1): BT hizmetinin kullanıcıların isteği üzerine özelleștirilebilme derecesidir.

Girişim (HU2): BT servisinin kullanıcıların hedeflerini tanıması ve servisin kullanıcıların ihtiyaçlarını karșılaması için değișiklikler önerme derecesidir.
Tablo 10: BT Hizmeti Uyarlanabilirliği Kriterine göre Ağırlıkların Belirlenmesi

\begin{tabular}{|l|l|l|l|}
\hline & HU1 & HU2 & Önem Seviyesi \\
\hline HU1 & 0,600273 & 0,600273 & $\mathbf{0 , 6 0 0 2 7 3}$ \\
\hline HU2 & 0,399727 & 0,399727 & $\mathbf{0 , 3 9 9 7 2 7}$ \\
\hline & & & $\mathbf{1 , 0 0 0 0 0 0}$ \\
\hline
\end{tabular}

Tablo 10'daki Özelleștirilebilirlik ve Girișim kriterlerinin almış olduğu değerlere göre en önemli unsur Özelleştirilebilirlik (0,600273) iken katılımcllara göre Girișim $(0,399727)$ unsuru daha az önemli durumdadır.

BT Servis Bakım Kolaylı̆g ana kriterinin alt kriterlerine göre yapılan ve alt kriterlerinin ağırlıklarını gösteren sonuç tablosu Tablo 11 'de gösterilmektedir. Alt kriterlere ilişkin bilgiler ise aşağıda verilmiștir:

Analiz Edilebilirlik (SB1): Eksiklikler, boşluklar ve arızalar için bir BT servisinin analiz edilebileceği etkililik ve verimlilik derecesidir.

Değiştirilebilirlik (SB2): Bir BT servisinin mevcut servis kalitesini bozulma olmadan etkili ve verimli bir şekilde değiştirilebileceği derecedir.

Test Edilebilirlik (SB3): Bir BT hizmeti için test kriterlerinin belirlenebileceği etkililik ve verimlilik derecesidir. Hizmet kriterlerinin karşılanıp karşılanmadığını belirlemek için testler yapılabilir.

Tablo 11: BT Servis Bakım Kolaylığı Kriterine göre Ağırlıkların Belirlenmesi

\begin{tabular}{|l|l|l|l|l|}
\hline & SB1 & SB2 & SB3 & Önem Seviyesi \\
\hline SB1 & 0,362582 & 0,354081 & 0,371731 & $\mathbf{0 , 3 6 2 7 9 8}$ \\
\hline SB2 & 0,334813 & 0,326963 & 0,318029 & $\mathbf{0 , 3 2 6 6 0 2}$ \\
\hline SB3 & 0,302605 & 0,318956 & 0,310241 & $\mathbf{0 , 3 1 0 6 0 1}$ \\
\hline & & & & $\mathbf{1 , 0 0 0 0 0 0}$ \\
\hline
\end{tabular}

\section{$C I=0,000323868 \quad C R=0,000558392$}

$\mathrm{Bu}$ veriler doğrultusunda Katılımcllarca belirlenen en önemli unsurun Analiz Edilebilirlik (0,362798) olduğu açıkça görülmektedir. $\mathrm{Bu}$ kriteri Değiștirilebilirlik $(0,326602)$ izlerken en az önemli unsur ise Test Edilebilirliktir (0,310601).
Katılımcılardan elde edilen verilere göre hesaplaması yapılan alt kriterlere ilişkin önem dereceleri özet olarak Tablo 12'de gösterilmektedir. 
Tablo 12: AHP ile Elde Edilen Yerel ve Genel Önem Dereceleri Siralaması

\begin{tabular}{|c|c|c|}
\hline & \begin{tabular}{|ll} 
Yerel & Önem \\
Derecesi &
\end{tabular} & \begin{tabular}{|ll} 
Genel & Önem \\
Derecesi &
\end{tabular} \\
\hline Tamlık & 0,199764 & 0,015498 \\
\hline Doğruluk & 0,248572 & 0,019285 \\
\hline Uygunluk & 0,290471 & 0,022536 \\
\hline Tutarlılık & 0,261192 & 0,020264 \\
\hline İhtiyaçlara Uygunluk & 0,151314 & 0,019270 \\
\hline Öğrenilebilirlik & 0,164954 & 0,021007 \\
\hline İşletilebilme & 0,159032 & 0,020253 \\
\hline Kullanıcı Hatası Önleme & 0,213484 & 0,027188 \\
\hline Erişilebilirlik & 0,197494 & 0,025151 \\
\hline Nezaket & 0,113723 & 0,014483 \\
\hline Gizlilik & 0,304381 & 0,029710 \\
\hline Bütünlük & 0,365419 & 0,035668 \\
\hline İzlenebilirlik & 0,330199 & 0,032230 \\
\hline Süreklilik & 0,328249 & 0,043331 \\
\hline $\begin{array}{l}\text { BT } \\
\text { İyileștirilebilirliği }\end{array}$ & 0,292221 & 0,038575 \\
\hline Kullanılabilirlik & 0,379530 & 0,050100 \\
\hline Görünürlük & 0,326611 & 0,049879 \\
\hline Profesyonellik & 0,404947 & 0,061842 \\
\hline $\begin{array}{l}\text { BT Servis Arabirimi } \\
\text { Görünümü }\end{array}$ & 0,268441 & 0,040996 \\
\hline Dakiklik & 0,434552 & 0,043124 \\
\hline $\begin{array}{ll}\text { Sorunlara } & \text { Cevap } \\
\text { Verebilme } & \end{array}$ & 0,565448 & 0,056114 \\
\hline Özelleştirilebilirlik & 0,600273 & 0,096906 \\
\hline Girişim & 0,399727 & 0,064530 \\
\hline Analiz Edilebilirlik & 0,362798 & 0,055167 \\
\hline Değiștirilebilirlik & 0,326602 & 0,049663 \\
\hline Test edilebilirlik & 0,310601 & 0,047230 \\
\hline
\end{tabular}

Yerel önem düzeyleri göz önüne alınarak Uygunluk ana kriterinin alt kriterleri sirasiyla Uygunluk, Tutarlılık, Doğruluk, Tamlık; Kullanış̧lılık ana kriterinin alt kriterleri sırasıyla, Kullanıcı Hatası Önleme, Erișilebilirlik, Öğrenilebilirlik, İșletilebilme, İhtiyaçlara Uygunluk, Nezaket; Güvenlik ana kriterinin alt kriterleri Bütünlük, İzlenebilirlik, Gizlilik; BT Servis Güvenlï̆i ana kriterinin alt kriterleri Kullanılabilirlik, Süreklilik, BT Hizmeti İyileștirilebiliriliği; Somutluk ana kriterinin alt kriterleri sırayla Profesyonellik, Görünürlük, BT Servis Arabirimi Görünümü; Heveslilik ana kriterinin alt kriterleri Sorunlara Cevap Verebilme, Dakiklik; $B T$ Hizmet Uygulanabilirliği ana kriterinin alt kriterleri Özelleştirilebilirlik, Girişim ve son olarak BT Servis Bakım Kolaylığı ana kriterine ait alt kriterler ise Analiz Edilebilirlik, Değiştirilebilirlik ve test edilebilirlik olarak sıralanmaktadır.

Genel önem düzeylerine bakıldığında ise en önemli üç alt kriter olarak sırasıyla Özelleștirilebilirlik, Girişim ve Profesyonellik olarak belirlenmiştir. Bu kriterler kullanıcıların otel yönetim sistemleri için aldıkları hizmetin uygulanabilir olması ve hizmet sunucunun hizmet sunmada hevesli olması yönündeki beklentilerini ortaya çıkartan önemli bulgulardır.

\section{4 | SONUÇ VE ÖNERÍLER}

$\mathrm{Bu}$ çalışmada turizm endüstrisinde konaklama hizmeti veren işletmelerin kullandıkları bilgi sistemleri için aldıkları hizmetin kalitesinin ölçümü için işletmelerdeki kurumsal kullanıcılara ISO/IEC TS 25011:2017 yazılım kalite sistemi faktörleri ele alınarak hazırlanan karşılaştırma formu uygulanmıştır. Elde edilen veriler Analitik Hiyerarşi Süreci (AHP) ile işlenerek ana kriter ve alt kriterler için önem dereceleri elde edilmiştir. Ana Kriterlere bakıldığında 0,161436 sonucu ile en büyük önem düzeyine sahip kriter "BT Hizmeti Uyarlanabilirliğidir. 0,152717 sonucu ile ikinci önemli kriter Somutluk olarak saptanmıştır. Diğer kriterler ise önem sırasına göre BT Servis Bakım Kolaylığı, BT Servis Güvenilirliği, Kullanışlılık, Heveslilik, Güvenlik ve Uygunluktur.

En yüksek önem düzeyine sahip olan "BT Hizmeti Uyarlanabilirliği", bilişim teknolojileri hizmetinin süreç içinde ortaya çıkan yeni düzenleme gereksinimlerini karşlayacak şekilde yapılandırılmasını ifade etmektedir. Araştırma sonucuna göre kullanıcların belirlediği en önemli kriterin gelişen teknoloji ve ihtiyaçların karşısında satın aldıkları yazılımın bu sürece hızlı bir şekilde adapte edilebilmesidir.

Tablolar incelendiğinde ortaya çıkan sonuçlar içinde ikinci en yüksek önem düzeyine sahip kriter olan "Somutluk" ise bilişim teknolojileri hizmetinin somut yönlerinin hizmeti etkili bir şekilde iletme ve destekleme derecesidir. Araştırmaya göre 
katılımcıların yazılımdan beklediği en önemli ikinci kriter kullanılan bilgi teknolojileri ile ilgili olarak istedikleri sonuca hızlı bir şekilde ulaşma ve bu sonucun desteklenmesidir.

Genel önem düzeyi tablosu incelendiği zaman kullanıcıların ilk olarak yerel önem düzeyi sonucu ile doğru orantılı olarak "Özelleștirilebilirlik" kriterini belirlediği ortaya çıkmaktadır. Özelleştirilebilirlik ifadesi anlam olarak bilişim teknolojileri hizmetinin kullanıcıların isteği üzerine özelleștirilebilme derecesidir. Kullanıcıların genel önem düzeyinde ilk sırada belirlemiş olduğu bu kriter, ilk sırada bulunan BT Hizmeti Uyarlanabilirliği ana kriteri ile anlamsal açıdan doğru orantılıdır. Kullanıcılar satın alacakları yazılımdan kendi ihtiyaçları doğrultusunda özelleştirilebilir olmasını beklemektedir.

İkinci genel önem düzeyi olarak "girişim" BT servisinin kullanıcıların hedeflerini tanıması ve hizmetin kullanıcıların ihtiyaçlarını karşılaması için değişiklikler önerme derecesini ifade etmektedir. Üçüncü genel önem düzeyi olarak "profesyonellik" ise bilişim teknolojileri hizmetlerinin uygun eğitim, beceri, uzmanlık ve yeterliliğe sahiplik derecesini ifade eder Özetle, kullanıcılar otel yönetim sistemi yazılımı hizmetini alırken uzman, yetenekli ve yeterliliğe sahip kişilerden almayı istemektedirler ve böylelikle olası sorunlara da hızlı bir şekilde yanıt verilmesini önemsedikleri söylenebilir.

Yapılan çalışmada elde edilen sonuçlar, Turizm ve Konaklama İşletmelerinin kullandıkları yazılım alanlarında çalışma yapacak kişiler ve firmalar için hangi faktörler üzerinde durmaları gerektiği konusunda yol gösterici olabilecek ve bilgi sağlayarak otel yönetim sistemleri özelinde sunulacak hizmetin kalitesinin sürekli gelişimini destekleyebilecek niteliktedir.

Daha önce de belirtildiği gibi literatürde ISO standartları baz alınarak ya da diğer hizmet kalitesi ölçeklerine dayanarak otel yönetim sistemleri seçimine yönelik bir çalışma olmaması çalışmanın tartışma kısmı ile ilgili bir kısıt oluşturmakla birlikte çalışmanın özgün yönünü de arttırmaktadır. Bu çalışma ile ISO/IEC TS 25011:2017 yazılım kalite sistemi faktörleri özelinde de akademik açıdan bir farkındalık oluşturulabileceği düşünülmektedir.

$\mathrm{Bu}$ çalışma İzmir ili şehir merkezinde bulunan 5 yıldızlı konaklama işletmeleri için kullanılan Otel Yönetim Sistemi yazılımı kullanıcılarından elde edilen verileri kapsamaktadır ve bu yüzden genelleme yapamamak çalışmanın önemli bir kısıtını oluşturmaktadır. İlerleyen çalışmalarda bu kısıtın aşılabilmesi için örneklemin çoğaltılarak odak grup görüşmeleri yapılarak ya da Delphi Tekniği ile veri toplanarak hizmetten beklentiler ve hizmetin kalitesini arttıracak öneriler için destekleyici nitelikte çalışmalar yapılabilir. Bunun yanı sıra otel yönetim sistemleri kullanıcılarının yazılım hizmet kalite beklentilerinin yanı sıra otel yönetim sistemi yazılımı üreten tarafın da kalite öncelikleri tespit edilerek karşılaştırmalı çalışmalar yapılabilir. Bu çalışmada kullanılan AHP yönteminin yanı sıra diğer çok kriterleri karar verme teknikleri ile karma modeller ve bulanık modeller oluşturularak önceliklendirme yapılabilir. 


\section{KAYNAKÇA}

Barutçugil, İ. (2002). Bilgi Yönetimi. İstanbul: Kariyer Yayıncllk.

Bitarafan, M., Hosseini, S. B., Abazarlou, S., \& Mahmoudzadeh, A. (2015). Selecting the optimal composition of architectural forms from the perspective of civil defense using AHP and IHWP methods. Architectural Engineering and Design Management, 11(2), 137-148.

Bruque, S., \& Medina, J. A. (2002). The technology paradox: characteristics, causes and implications for IT management. International Journal of Information Technology, 8(1), 75-94.

Celep, C., Çetin B. (2003). Bilgi yönetimi: Örgütlerde bilgi paylaşım kültürü yaratma. Anı yayıncılık.

Çakır, O. (2008). The grey extent analysis. Kybernetes: The International Journal of Systems \& Cybernetics, 37(7), 997-1015.

Çakır, O. (2012). A compensatory model for computing with words under discrete labels and incomplete information. Knowledge-Based Systems, 27, 29-37.

Emeksiz, M. (2002). Beş yıldızlı otel işletmeleri için getiri yönetimi uygulama modeli. Anadolu Üniversitesi Turizm ve Otel İșletmeciliği Yüksekokulu. Eskişehir: Anadolu Üniversitesi Yayınları.

https://iso.org. (2017). Information technology Systems and software Quality Requirements and Evaluation (SQuaRE) - Service quality models: https://www.iso.org/standard/35735.html adresinden alındı

Ham, S., Kim, W. G., \& Jeong, S. (2005). Effect of information technology on performance in upscale hotels. International journal of hospitality management, 24(2), 281-294.

Law, R., \& Jogaratnam, G. (2005). A study of hotel information technology applications. International Journal of Contemporary Hospitality Management.

Melvin, A. (2012). Decision-Making using the Analytic Hierarchy Process (AHP) and SAS/IML, Ed. 20th Annual South East SAS Users Group, Durham, NC.

Met, Ö., Erdem, B. (2006). Konaklama İşletmelerinde Verimliliğin Ölçülmesi ve Verimliliği Etkileyen Etkenlerin Analizi. Gazi Üniversitesi Ticaret ve Turizm Eğitim Fakültesi Dergisi, (2), 53-73.

Offsey, S. (1997). Knowledge management: linking people to knowledge for bottom line results. Journal of knowledge management, 1(2), 113-122.

Oğuzlar, A. (2007). Analitik Hiyerarşi Süreci İle Müşteri Şikayetlerinin Analizi. Akdeniz University Faculty of Economics \& Administrative Sciences
Faculty Journal/Akdeniz Universitesi Iktisadi ve Idari Bilimler Fakultesi Dergisi, 7(14).

Ömürbek, N., Makas, Y., \& Ömürbek, V. (2015). Ahp ve Topsıs Yöntemleri İle Kurumsal Proje Yönetim Yazılımı Seçimi. Journal of Suleyman Demirel University Institute of Social Sciences, 21(1).

Saaty, T. L. (1988). What is the analytic hierarchy process? In Mathematical models for decision support (pp. 109-121). Springer, Berlin, Heidelberg.

Saaty, T. L. (1990). How to make a decision: the analytic hierarchy process. European journal of operational research, 48(1), 9-26.

Sheldon, P. J. (1983). The impact of technology on the hotel industry. Tourism Management, 4(4), 269-278.

Samut, P. K. (2014). İki Aşamalı Çok Kriterli Karar Verme ile Performans Değerlendirmesi: AHP ve TOPSIS Yöntemlerinin Entegrasyonu. Anadolu University Journal of Social Sciences, 14(4), 57-67.

Şencan, E. (2013). Bilgi Yönetimi ve Sanal Halkla IIlişskiler. Konya : Eğitim Yayınevi .

Tüzemen, A., \& Özdağoğlu, A. (2007). Doktora öğrencilerinin eş seçiminde önem verdikleri kriterlerin analitik hiyerarşi süreci yöntemi ile belirlenmesi. Atatürk Üniversitesi Íktisadi ve İdari Bilimler Dergisi, 21(1), 215-232.

Xiang, Y., Zhou, W., \& Chowdhury, M. (2003, December). GHIRS: integration of hotel management systems by web services. In International Conference on Grid and Cooperative Computing (pp. 1002-1009). Springer, Berlin, Heidelberg.

Vianna, R. H. P., Fonseca, F., Mello, A. M., \& Nascimento, P. T. (2014). ERP adoption in the hotel industry: How software implementation becomes development. In Proceedings of PICMET'14 Conference: Portland International Center for Management of Engineering and Technology; Infrastructure and Service Integration (pp. 33673375). IEEE.

Yaralığlu, K. (2004). Uygulamada Karar Destek Yöntemleri. İzmir: İlkem Ofset Basım.

Yeniçeri, Ö. ve İnce, M. (2005). Bilgi Yönetim Stratejileri ve Girişimcilik, İstanbul: IQ Kültür Sanat Yayıncllık.

Zaim, H. (2005). Bilginin Artan Önemi ve Bilgi Yönetimi. İstanbul: İşaret Yayınları.

Zhao, J. L. (1998). Globalizations, Multinationals and Corporate Strategies. M. O. vd. içinde, Strategic Management in the Hospitality Industry. John Wiley and Sons Inc. 